activation of the temporoparietal junction, ${ }^{8}$ then we will need to pay more than lip service to building multidimensional models of psychopathology.

Stephen J. Wood, MA(Cantab), PhD, Orygen, The National Centre for Excellence in Youth Mental Health, 35 Poplar Road, Parkville, Victoria 3052, Australia. Email: stephen.wood@orygen.org.au

First received 23 Nov 2016, accepted 19 Jan 2017

\section{References}

1 Bleuler E. Dementia Praecox or the Group of Schizophrenias. International Universities Press, 1950

2 Bender L. Childhood schizophrenia. Am J Orthopsychiatry 1947; 17: 40-56.
3 Rutter M. Childhood schizophrenia reconsidered. J Autism Dev Disord 1972; 2: $315-37$.

4 Chisholm K, Lin A, Abu-Akel A, Wood SJ. The association between autism and schizophrenia spectrum disorders: a review of eight alternate models of co-occurrence. Neurosci Biobehav Rev 2015; 55: 173-83.

5 Larson FV, Wagner AP, Jones PB, Tantam D, Lai M-C, Baron-Cohen S, et al. Psychosis in autism: a comparison of the features of both conditions in a dually-affected cohort. Br J Psychiatry 2017: 210: 269-75.

6 Werling DM, Geschwind DH. Sex differences in autism spectrum disorders. Curr Opin Neurol 2013; 26: 146-53.

7 Abu-Akel A, Wood SJ, Hansen PC, Apperly IA. Perspective-taking abilities in the balance between autism tendencies and psychosis proneness. Proc Bio Sci 2015; 282: 20150563.

8 Abu-Akel A, Apperly IA, Wood SJ, Hansen PC. Autism and psychosis expressions diametrically modulate the right temporoparietal junction. Soc Neurosci 2016; June 3 (Epub ahead of print).

\section{psychiatry in pictures}

\title{
Simba Muzira
}

Sara Muzira

These images are from an exhibition of Simba Muzira's work titled 'Doing it again'. The exhibition runs at the Long Gallery, Maudsley Hospital, from 1 February to 1 May 2017. Simba was a patient at the Maudsley on several occasions from 2012 unti his death in 2015, aged 32. For more information, see www.slam.nhs.uk/about-us/art-and-history/maudsley-long-gallery
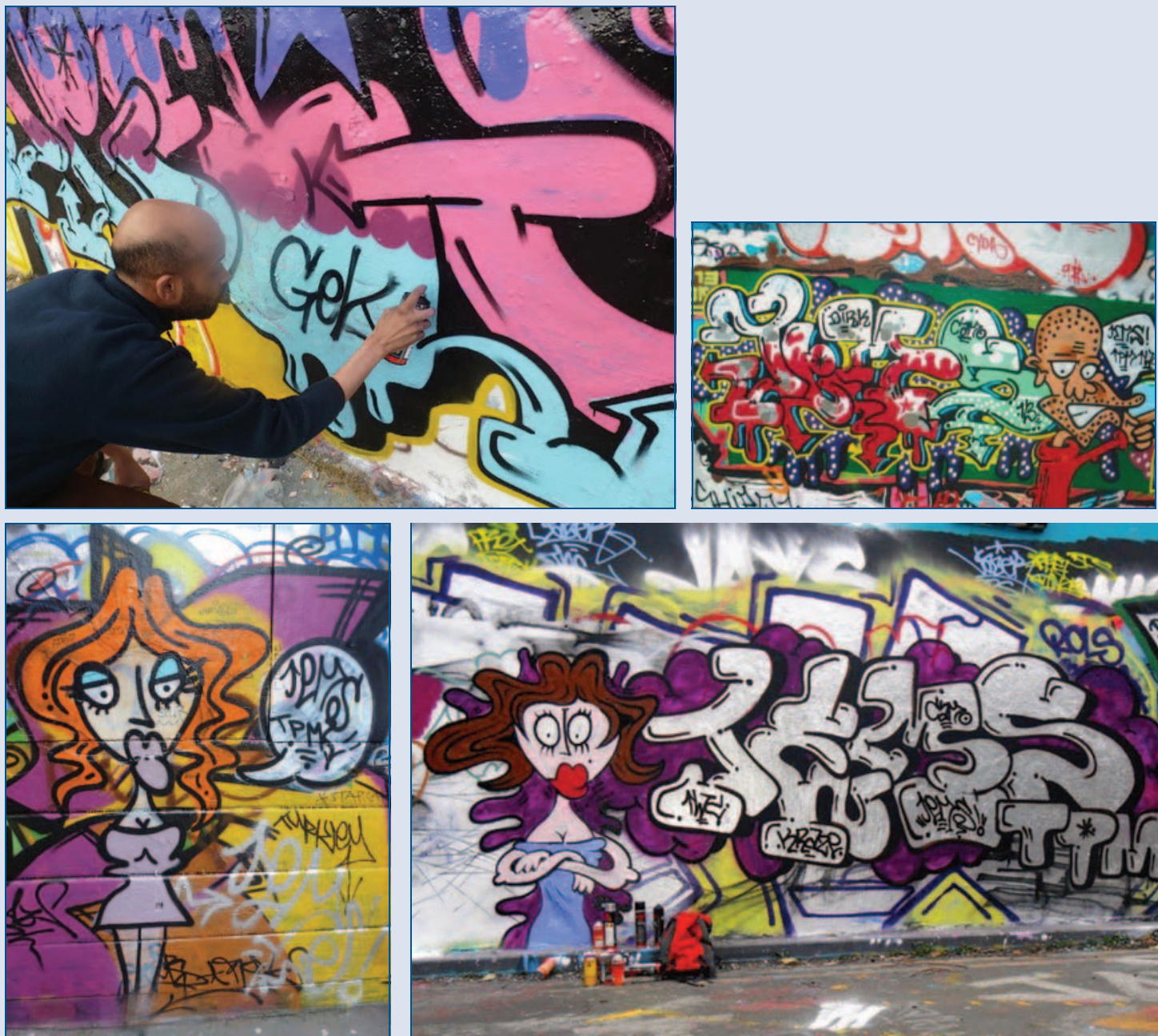